\title{
Sobre Hemilophini (Coleoptera, Cerambycidae, Lamiinae) da Região Neotropical: espécies novas e novos registros
}

\author{
Ubirajara R. Martins ${ }^{1,3}$ \& Maria Helena M. Galileo ${ }^{2,3}$ \\ ${ }^{1}$ Museu de Zoologia, Universidade de São Paulo. Caixa Postal 42494, 04218-970 São Paulo, São Paulo, Brasil. \\ 2 Museu de Ciências Naturais, Fundação Zoobotânica do Rio Grande do Sul. Caixa Postal 1188, 90001 -970 Porto Alegre, \\ Rio Grande do Sul, Brasil. \\ ${ }^{3}$ Bolsista do CNPq.
}

\begin{abstract}
On Neotropical Hemilophini (Coleoptera, Cerambycidae, Lamiinae): new species and new records. New species described from Panama: Adesmus acangauna sp. nov., $A$. windsori sp. nov., $A$. hovorei sp. nov., Sybaguasu anemum sp. nov., Iareonycha albisterna sp. nov., and from Bolivia (Santa Cruz): Phoebe alba sp. nov. and Purusia wappesi sp. nov. New records: Adesmus divus (Chabrillac, 1857), A. nevisi (Gounelle, 1909), Apypema yara Galileo \& Martins, 1992, Cuicirama spectabilis (Blanchard, 1843), Phoebe ornator (Tippmann, 1960), Purusia acreana Lane, 1956 and Zeale dubia Galileo \& Martins, 1997. A key to the species of Sybaguasu Martins \& Galileo, 1991 is added. KEY WORDS. Adesmus, Iareonycha, Phoebe, Purusia, Sybaguasu.
\end{abstract}

RESUMO. Novas espécies descritas do Panamá: Adesmus acangauna sp. nov., $A$. windsori sp. nov., $A$. hovorei sp. nov., Sybaguasu anemum sp. nov., Iareonycha albisterna sp. nov., e da Bolívia (Santa Cruz): Phoebe alba sp. nov. e Purusia wappesi sp. nov. Novos registros: Adesmus divus (Chabrillac, 1857), A. nevisi (Gounelle, 1909), Apypema yara Galileo \& Martins, 1992, Cuicirama spectabilis (Blanchard, 1843), Phoebe ornator (Tippmann, 1960), Purusia acreana Lane, 1956 e Zeale dubia Galileo \& Martins, 1997. Acrescenta-se chave para espécies de Sybaguasu Martins \& Galileo, 1991. PALAVRAS CHAVE. Adesmus, Iareonycha, Phoebe, Purusia, Sybaguasu.

Com base nas coleções de F.T. Hovore, de R.H. Turnbow e do American Coleoptera Museum, descrevemos sete novas espécies de Hemilophini e apresentamos novos registros.

Em Adesmus Lepeletier \& Audinet-Serville, 1825, gênero revisto recentemente por Galileo \& Martins (1999), são descritas três espécies do Panamá. Em Phoebe Audinet-Serville, 1835, também revisto por esses autores (Martins \& Galileo 1998), acrescentamos espécie nova da Bolívia.

A segunda espécie do gênero Iareonycha Martins \& Galileo, 1997 é descrita do Panamá, gênero cujas espécies apresentam duas carenas contíguas em cada élitro.

Sybaguasu foi estabelecido por Martins \& GaLILEO (1991). Incluímos chave para espécies do gênero com a descrição de mais uma nova espécie do Panamá que apresenta acentuado dimorfismo sexual na coloração do protórax.

Em Purusia Lane, 1956, até agora gênero monotípico, acrescentamos uma segunda espécie da Bolívia com elaborado padrão de colorido dos élitros.

As siglas citadas no texto correspondem: American Coleoptera Museum, Bulverde, Texas, (ACMB); Coleção F.T. Hovore, Santa Clarita, California (FTHC); Museu de Ciências
Naturais, Fundação Zoobotânica do Rio Grande do Sul, Porto Alegre (MCNZ); Museo de Historia Natural, Noel Kempff Mercado, Santa Cruz (MNKM); Museu de Zoologia, Universidade de São Paulo, São Paulo (MZSP); Coleção R.H. Turnbow, Fort Rucker, Alabama (RHTC) e United States National Museum, Washington (USNM). O depósito dos holótipos no MNKM e no USNM foi uma determinação de J.E. Wappes (ACMB), responsável pelo envio do material para estudo.

\section{Phoebe ornator (Tippmann, 1960)}

Adesmus ornator Tippmann, 1960: 204, est. 13, fig. 32b.

Phoebe ornator; Martins \& Galileo, 1993: 113; 1998: 432 (chave).

Descrita de Yungas del Palmar, Bolívia e assinalada para Cochabamba, Villa Tunari $\left(16^{\circ} 55^{\prime} \mathrm{S}, 6^{\circ} 22^{\prime} \mathrm{W}\right)$ e para Leopoldo Bulhões ( $16^{\circ} 37^{\prime} \mathrm{S}, 48^{\circ} 46^{\prime} \mathrm{W}$ ), Goiás, Brasil por MARTINs \& GALILEO (1993). Ampliamos a distribuição na Bolívia.

Material examinado. Bolívia, Santa Cruz: Buena Vista (46 km SSE, Hotel Flora e Fauna, 430 m), macho, 22-31.X.2002, Wappes \& Morris leg. (ACMB).

Revista Brasileira de Zoologia 21 (3): 535-541, setembro 2004 


\section{Phoebe alba sp. nov.}

Fig. 1

Etimologia. Latim, albus = branco; alusivo a pubescência branca compacta do corpo.

Cabeça com tegumento castanho-avermelhado; fronte glabra; pubescência branca, densa, reveste uma faixa transversal entre os tubérculos anteníferos e uma área grande atrás dos lobos oculares superiores até o occipício que ocupa todo o dorso da cabeça. Fronte (fêmea) com duas gibosidades arredondadas no topo. Olhos inteiros. Lobos oculares superiores mais próximos entre si do que a largura de um lobo. Escapo preto; atinge aproximadamente o meio do protórax. Pedicelo e flagelômeros alaranjados. Protórax castanho-avermelhado. Pronoto coberto por pubescência branca, compacta, menos em duas faixas curtas e estreitas situadas de cada lado do meio. Partes laterais do protórax quase glabras. Élitros com tegumento vermelho-acastanhado; dorso (Fig. 1) revestido por pubescência branca, compacta; epipleuras castanho-avermelhadas com quatro prolongamentos curtos, em direção à sutura, o mais apical é o único que a atinge; para trás deste último prolongamento, os élitros são ocupados por mancha branca que envolve as epipleuras. Pernas alaranjadas. Coxas recobertas por pubescência branca. Face ventral do corpo castanho-avermelhada, revestida por pubescência branca, mais esparsa no mesosterno, no centro do metasterno e dos urosternitos. Pubescência branca, compacta, recobre: a parte externa do mesosterno, a parte interna dos mesepimeros e dos mesepisternos, os metepimeros e os lados do metasterno e dos urosternitos.

Dimensões em milímetros, holótipo fêmea. Comprimento total, 14,1; comprimento do protórax, 2,4; maior largura do protórax, 2,7; comprimento do élitro, 10,5; largura umeral, 3,5.

Material-tipo. Holótipo fêmea, Bolívia, Santa Cruz: Buena Vista, XI-XII.1992, R. Clarke leg. (MNKM).

Discussão. Phoebe alba sp. nov. distingue-se de Phoebe spegazzinii Bruch, 1908 pelo pedicelo alaranjado, pela ausência de faixas pretas no vértice, no occipício e no pronoto, pelas partes laterais do protórax castanho-avermelhadas, pelo padrão de colorido dos élitros, pela pubescência que reveste o metasterno menos em estreita região centro-longitudinal. Em P. spegazzinii o pedicelo é preto; cabeça e pronoto têm três faixas pretas ou avermelhadas; as partes laterais do protórax são revestidas por pubescência branca menos em duas áreas; os élitros têm seis ou sete manchas pretas ou avermelhadas e apenas o extremo lateral do metasterno é revestido por pubescência branca.

Phoebe ornator (Tippmann, 1960) que também ocorre na Bolívia, difere de $P$. alba pelo escapo alaranjado, pelos antenômeros apicais pretos, pela ausência de manchas na cabeça e no protórax, pelas extremidades elitrais ocupadas por faixa preta e pelos metepisternos e metepimeros inteiramente revestidos por pubescência branca.

\section{Zeale dubia Galileo \& Martins, 1997}

Zeale dubia Galileo \& Martins, 1997: 162, fig. 3.

Discussão. Espécie descrita originalmente da Bolívia, Pando (Cobija) e Santa Cruz (San Ignacio). Ora registramos para Cochabamba.

Material examinado. Bolívia, Cochabamba: Villa Tunari (240 m), macho, 2-6.IX.1983, R. Wilkerson leg. (ACMB).

\section{Adesmus divus (Chabrillac, 1857)}

Hemilophus divus Chabrillac, 1857: 200.

Amphionycha diva; Bates, 1881: 303.

Adesmus divus; Aurivillius, 1923: 589 (cat.); Monné, 1995: 24

(cat.); Galileo \& Martins, 1999: 93, fig. 4.

Amphionycha procera Gahan, 1889: 399; Martins \& Galileo, 1993 :

113 (sin.).

ZaCjIw (1967) arrolou A. divus para o Brasil, Goiás (Goiânia), São Paulo (Batatais, Marília), Paraná (Rolândia), para o Paraguai e para a Argentina (Misiones). A distribuição foi ampliada no Brasil por Martins \& Galileo (1993): Mato Grosso (Chapada dos Guimarães), Distrito Federal (Brasília, Lago Sul) e Minas Gerais (Pirapora); Galileo \& Martins (1999) acrescentaram o Rio Grande do Sul (São Borja, Garruchos).

Material examinado. Bolívia, Santa Cruz: Buena Vista (Hotel Flora e Fauna, 4-6 km SSE), fêmea, 23-26.X.2000, Wappes $\&$ Morris leg. (ACMB).

\section{Adesmus nevisi (Gounelle, 1909)}

Amphionycha nevisi Gounelle, 1909: 83.

Adesmus nevisi; Aurivillius, 1923: 590 (cat.); Monné, 1995: 25

(cat.); Galileo \& Martins, 1999: 95, fig. 34.

Originalmente descrita com base em numerosos exemplares procedentes dos campos da região de Diamantina, Minas Gerais, Brasil. GALILEO \& MARTins (1999) acrescentaram, também no Brasil, Mato Grosso (Rosário Oeste), Distrito Federal (Brasília), Goiás (Formosa, Leopoldo Bulhões). Ora ampliamos a distribuição para a Bolívia.

Material examinado. Bolívia, Santa Cruz: Buena Vista (Hotel Flora e Fauna, 4-6 km SSE), fêmea, 22-31.X.2002, Wappes $\&$ Morris leg. (ACMB).

\section{Adesmus hovorei sp. nov.}

Fig. 2

Etimologia. O epíteto é uma homenagem ao Dr. Frank T. Hovore, Santa Clarita, California (FTHC), pelas inúmeras gentilezas.

Tegumento alaranjado; preto no lado externo do escapo. Cabeça revestida por densa pubescência branca, menos na fronte e nas genas que são glabras. Fronte pontuada. Antenas e pernas alaranjadas. Todo o protórax recoberto por pubescência branca. Élitros (Fig. 2) avermelhados com pubescência branca: 

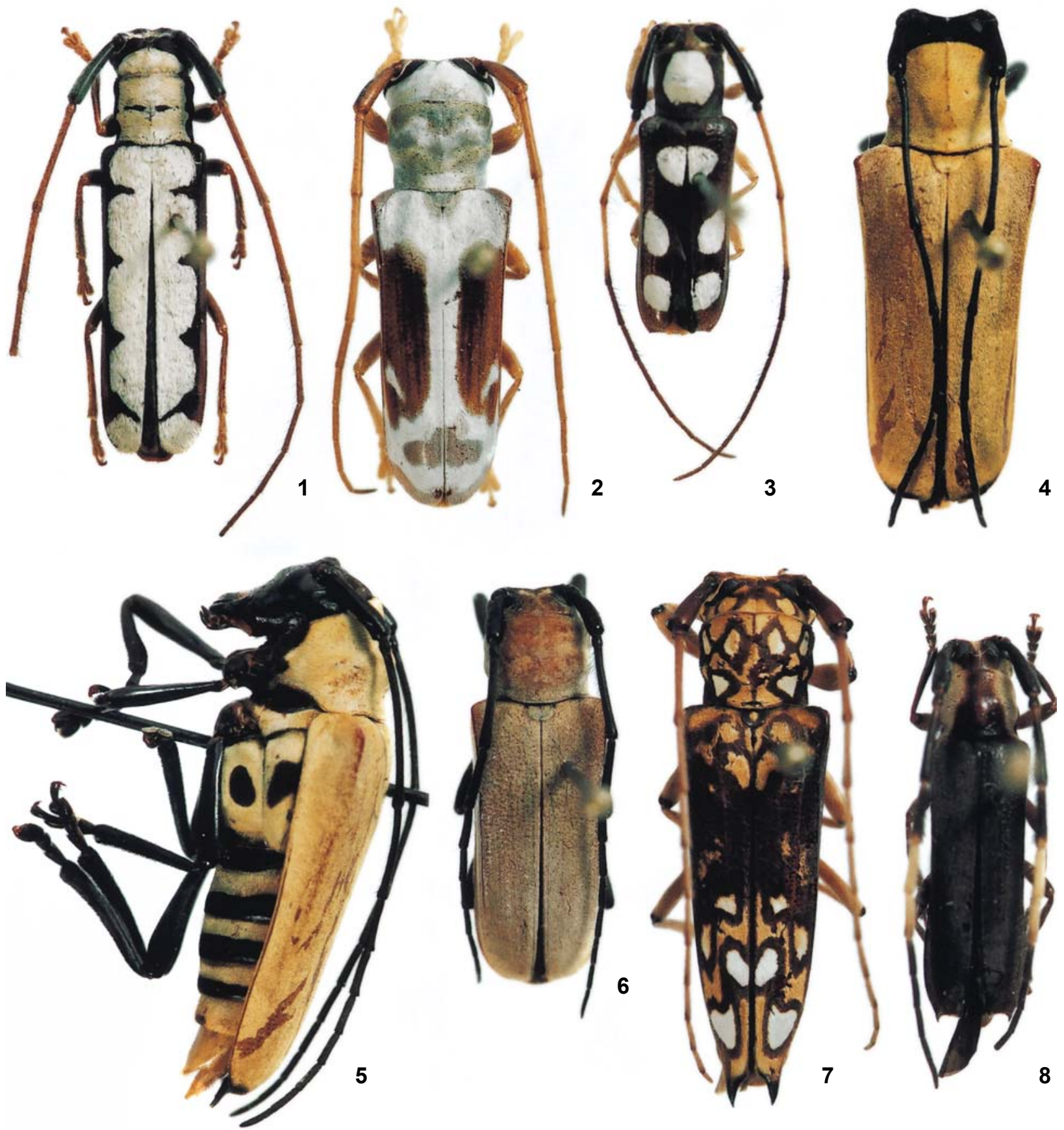

Figuras 1-8. Habitus. (1) Phoebe alba sp. nov., comprimento, 14,1 mm; (2) Adesmus hovorei sp. nov., comprimento, 16,3 mm; (3) A. windsori sp. nov., comprimento, 7,4 mm; (4-5) A. acangauna sp. nov., comprimento, 17,7 mm: (4) dorsal, (5) lateral; (6) lareonycha albisterna sp. nov., comprimento, 13,1 mm; (7) Purusia wappesi sp. nov., comprimento, 19,8 mm; (8) Sybaguasu anemum sp. nov., comprimento, 9,6 $\mathrm{mm}$.

numa faixa transversal que ocupa o quarto basal unida a uma faixa longitudinal, fundida com a sutura e prolongada até o terço apical, onde se dirige, oblíqua e descendente, para a mar- gem e segue circundando uma região transversal com pubescência mais esparsa em todo quarto apical; no terço apical e soldada à carena, pequena mancha oblíqua; borda apical dos

Revista Brasileira de Zoologia 21 (3): 535-541, setembro 2004 
élitros com faixa estreita de pubescência branca e esparsa; no terço anterior das epipleuras, pequena mancha de pubescência branca. Esternos torácicos revestidos por pubescência branca exceto prosterno e mesosterno. Urosternito I com uma mancha branca, a cada lado, atrás das metacoxas. Lados dos urosternitos II a IV com mancha de pubescência branca e esparsa.

Dimensões em milímetros, holótipo macho. Comprimento total, 16,3; comprimento do protórax, 3,4; maior largura do protórax, 3,9; comprimento do élitro, 11,5; largura umeral, 5,2.

Material-tipo. Holótipo macho, Panamá, Panamá: El Llano (Carti Road km 8-11, 1100 pés), 26.IV-2.V.1992, J.E. Wappes leg. (USNM). Parátipos - Panamá, Panamá: Fort Kobbe, macho, 18.V.1967, F.T. Hovore leg. (FTHC); El Llano (7-10 km N), fêmea, 21-30.IV.1995, E. Giesbert leg. (MZSP). Costa Rica, Heredia: La Selva Biol. Station, macho, IX.1996 (emgd, ex girdled twig), F.T. Hovore leg. (FTHC).

Discussão. São raras as espécies de Adesmus com o pronoto revestido por pubescência branca: A. collaris Melzer, 1931, A. postilenatus (Bates, 1881) e A. colligatus (Redtenbacher, 1867), mas todas essas tem élitros pretos ou pretos com manchas brancas (Galileo \& Martins 1999). A. hovorei sp. nov. difere de todas pelos élitros com tegumento avermelhado e o padrão da distribuição da pubescência branca (Fig. 2) muito característico.

\section{Adesmus windsori sp. nov. \\ Fig. 3}

Etimologia. O epíteto é uma homenagem a Don Windsor, Smithsonian Tropical Research Institute, Panamá, coletor do material-tipo.

Tegumento corporal vermelho-acastanhado. Escapo e pedicelo pretos. Flagelômeros e pernas amarelados. Fronte com pubescência branca menos numa área retangular na parte inferior que se aproxima do lobo inferior dos olhos. Vértice com faixa estreita de pubescência branca, situada atrás dos lobos oculares superiores. Franja de pêlos dos flagelômeros, moderada. Lobos oculares superiores mais próximos entre si do que a largura de um lobo. Centro anterior do pronoto com grande mancha subcircular de pubescência branca compacta que atinge a borda anterior. Partes laterais do protórax com faixa larga de pubescência branca compacta no limite com o prosterno e continuada pelo mesepimero, mesepisterno, lados do metasterno, metepisterno e lados dos urosternitos I a IV. Cada élitro (Fig. 3) com três manchas de pubescência branca compacta: uma triangular no quarto anterior fundida com a sutura; uma dorsal, no meio, subelíptica, que não toca a sutura; uma retangular, no quarto apical, que se funde com a sutura. Extremidades elitrais obliquamente truncadas com espículo no lado externo.

Dimensões em milímetros, holótipo fêmea. Comprimento total, 7,4-7,9; comprimento do protórax, 1,4-1,6; maior largura do protórax, 1,6-1,7; comprimento do élitro, 5,1-5,4; largura umeral, 2,1-2,4.

Material-tipo. Holótipo fêmea procedente do Panamá, Canal Zone: Barro Colorado (99'N, 7951'W), 14.VIII.1996,
Pickering \& Windsor leg. (USNM).

Parátipos - mesma localidade do holótipo, fêmea, 1118.V.1994, Pickering leg. (MZSP); macho, 2-9.XI.1994, Pickering \& Windsor leg. (RHTC); fêmea, 1.I.1997, Pickering \& Windsor leg. (ACMB); fêmea, 22.I.1997, Pickering \& Windsor leg. (MCNZ); 2 fêmeas, 29.I.1997, Pickering \& Windsor leg. (ACMB, RHTC); fêmea,16.VII.1997, Pickering \& Windsor leg. (MZSP); fêmea, 13.VIII.1997, Pickering \& Windsor leg. (ACMB); macho,1428.I.1998, Pickering \& Windsor leg., "Malaise trap" (MZSP); fêmea, 28.VII.1999, D. Windsor leg., Malaise trap (ACMB).

Discussão. Adesmus windsori sp. nov. separa-se de todas as espécies castanho-avermelhadas de Adesmus pela grande mancha arredondada do pronoto. Nas outras espécies castanho-avermelhadas de Adesmus, o pronoto é totalmente recoberto por pubescência branca ou tem faixa, de diversas larguras, no centro do pronoto. Além disso, são muito raras espécies de Adesmus com espículo no lado externo das pontas dos élitros, caráter presente em $A$. windsori.

\section{Adesmus acangauna sp. nov. Figs 4, 5}

Etimologia. Tupi, acanga = cabeça; una = preto; alusivo à coloração da cabeça.

Tegumento preto: cabeça, antenas, pernas, prosterno, mesosterno, parte anterior dos mesepimeros, manchas no meio do metepisterno e no meio do lado do metasterno, extremo apical dos élitros, metade apical dos urosternitos I a III. Tegumento avermelhado coberto por densa pubescência amarelada (Figs 4, 5): pronoto, partes laterais do protórax, élitros, metade basal dos urosternitos I a III, urosternitos IV e V. Fronte glabra com pontos esparsos. Vértice revestido por pubescência preta. Antenômero III com franja de pêlos esparsa no lado interno. Antenas atingem o ápice dos élitros na ponta do antenômero X. Pronoto com uma gibosidade no nível do terço posterior e inteiramente dotado de pubescência amarelada densa. Escutelo recoberto por pubescência amarelada. Urosternito $\mathrm{V}$ levemente emarginado.

Dimensões em milímetros, holótipo fêmea. Comprimento total, 17,7; comprimento do protórax, 3,8; maior largura do protórax, 4,9; comprimento do élitro, 13,1; largura umeral, 7,0.

Material-tipo. Holótipo fêmea procedente do Panamá, Bocas del Toro: 4 km N, Continental Divide, Gualaca-Chiriqui Grande Highway, 14.VI.1985, E. Riley \& D. Rider leg. (USNM).

Discussão. Não existem espécies conhecidas do gênero Adesmus com élitros inteiramente revestidos por pubescência uniforme amarelada com estreita região apical dos preta e urosternitos divididos, transversalmente, em duas porções, de preto e amarelado. Além disso, as duas manchas pretas em fundo amarelado no meio das partes laterais do metasterno e do metepisterno não são encontradas em nenhuma espécie do gênero. Em Adesmus acangauna sp. nov. esses caracteres são evidentes (Fig. 5). 


\section{Iareonycha albisterna sp. nov. \\ Fig. 6}

Etimologia. Latim, albus = branco; sterno = peito, alusivo aos esternos torácicos cobertos por pubescência branca.

Fronte, genas e pontas dos tubérculos anteníferos pretos. Vértice e occipício castanho-alaranjados cobertos por pubescência amarelada. Fronte com pontuação grossa e esparsa. Antenas pretas. Franja de pêlos dos antenômeros basais moderadamente abundante. Protórax com tubérculos laterais pouco projetados. Disco pronotal e élitros castanho-alaranjados com pubescência densa amarelada (Fig. 6). Prosterno preto. Élitros com duas carenas contíguas e setas curtas, amareladas, em toda superfície; extremidades elitrais truncadas com vestígio de espículo no lado externo. Mesosterno, mesepimeros e mesepisternos, pretos. Metasterno preto a castanho-avermelhado coberto por densa pubescência branca que às vezes falta na região central. Metepisternos e metepimeros cobertos por pubescência branca. Pernas pretas. Urosternitos I-III ou II-III cobertos por pubescência branca, densa.

Dimensões em milímetros, fêmea. Comprimento total, 13,1-14,5; comprimento do protórax, 3,0-3,2; maior largura do protórax, 3,2-3,5; comprimento do élitro, 10,0-10,5; largura umeral, 4,3-4,8.

Material-tipo. Holótipo fêmea, PANAMÁ, Panamá: Nusagardi area (Cordillera Igar, trail), 9.VI.1985, E. Riley \& D. Rieder leg. (USNM). Parátipo fêmea, Panamá, Panamá: Cerro Jefe, 9.VI.1985, E. Riley \& D. Rieder leg. (MZSP).

Discussão. Iareonycha albisterna sp. nov. difere de $I$. ipepuna Martins \& Galileo, 1997 pela fronte, partes laterais do protórax e prosterno pretos; pelos élitros inteiramente castanho-alaranjados com pubescência amarelada; pelo metasterno e metepisternos com pubescência branca. Em I. ipepuna as partes laterais do protórax e o prosterno são alaranjados; os élitros, o metasterno e os metepisternos são pretos.

\section{Purusia wappesi sp. nov.}

Fig. 7

Etimologia. O epíteto é uma homenagem a Jim E. Wappes $(\mathrm{ACMB})$ que nos enviou para estudo vultoso material.

Tegumento castanho-avermelhado. Vértice e occipício com pubescência amarelada numa faixa transversal à frente dos lobos oculares superiores; duas manchas de pubescência mais esparsa atrás dos lobos oculares superiores; faixa longitudinal, estreita, atrás dos olhos na altura do menor estreitamento; três manchas na parte posterior do vértice: uma de cada lado, subarredondadas e mancha central no occipício; mancha longitudinal, nos lados da cabeça, atrás dos lobos oculares inferiores. Lados da fronte dos machos com duas elevações terminadas no nível dos lobos inferiores dos olhos por tubérculos arredondados no topo. Antenas avermelhadas com 12 artículos. Região apical do escapo com cicatriz circundada por pequena carena.

Protórax mais largo anteriormente do que na base, com manchas brancas e amareladas; as brancas: quatro na metade anterior e duas nos lados da base; as amareladas: três junto à borda anterior intercaladas entre as manchas brancas. Faixa irregular no meio emite ramos para ambos os lados do pronoto e termina em mancha basal entre as duas brancas. Todas as manchas pronotais circundadas por pubescência castanhoavermelhada. Partes laterais do protórax com faixa estreita, longitudinal, de pubescência branca no limite com o prosterno e em parte dos proepimeros.

Escutelo com uma mancha central de pubescência amarelada. Quinto basal dos élitros (Fig. 7) com manchas e faixas de pubescência amarelada: uma na base que envolve o escutelo e se prolonga, em pequena extensão, pela sutura; uma mancha dorsal, halteriforme, de cada lado e duas manchas próximas à sutura. No extremo posterior da metade basal dos élitros, duas manchas pequenas, irregulares, de pubescência amarelada. Terço apical com oito manchas brancas: duas dorsais, mais próximas da sutura, duas perto da carena lateral, duas soldadas à sutura e duas, maiores, próximas do ápice. Entre essas manchas de pubescência branca, faixa irregular de pubescência amarelada e entre as duas manchas apicais, faixa longitudinal, soldada à sutura que se alarga antes dos espinhos elitrais. Epipleura com pequena mancha amarelada subumeral. Carena umeral manifesta. Uma segunda carena pouco perceptível do quarto anterior ao meio. Extremidades prolongadas em robusto espinho preto.

Pubescência branca na face ventral: esparsa no prosterno, mesosterno e centro do metasterno; manchas densas, em forma de vírgula nos mesepisternos, nos mesepimeros, nos lados anteriores do metasterno, na metade anterior dos metepisternos, no urosternito IV com pequena mancha e no urosternito $\mathrm{V}$ com mancha bem desenvolvida. Pro- e mesotrocanteres e extremo apical dos fêmures, pretos. Garra interna das unhas tarsais apenas mais curta que a externa.

Dimensões em milímetros, holótipo fêmea. Comprimento total, 19,8; comprimento do protórax, 3,5; maior largura do protórax (junto à orla anterior), 4,2; comprimento do élitro, 15,0; largura umeral, 5,6.

Material-tipo. Holótipo fêmea, procedente da Bolívia, Santa Cruz: Buena Vista (3,7 km SSE, Hotel Flora e Fauna, 430 m), 15-22.XI.2001, B.R. Dozier leg. "blacklight trap, transition forest" (MNKM). Parátipo macho, mesma procedência do holótipo, 4-6 km SSE, 1-8.XI.2002, J. E. Wappes leg. (MZSP).

Discussão. O gênero Purusia Lane, 1956 continha única espécie, $P$. acreana cujos machos têm projeções frontais notáveis (Martins \& Galileo 1993: 111, figs 4, 5). Em P. wappesi sp. nov. os machos têm projeções separadas e localizadas nos lados da fronte. Além disso, o padrão de colorido separa largamente $P$. wappesi de $P$. acreana.

\section{Purusia acreana Lane, 1956}

Purusia acreana Lane, 1956: 29, fig. 5; Martins \& Galileo, 1993 : 111, figs 4, 5; Monné, 1995: 32 (cat.).

Originalmente descrita de Alto Purus, Acre e Óbidos (Co-

Revista Brasileira de Zoologia 21 (3): 535-541, setembro 2004 
lônia Rio Branco), Pará. Martins \& Galileo (1993) registraramna para o Peru e Brasil (Amazonas). O material ora examinado, reporta-a para a Bolívia.

Material examinado. Bolívia, Santa Cruz: Buena Vista (Hotel Flora e Fauna, 4-6 km SSE), macho, 22-31.X.2002, Wappes \& Morris leg. (ACMB).

\section{Sybaguasu Martins \& Galileo, 1991}

Sybaguasu Martins \& Galileo, 1991: 621 (Espécie-tipo, Saperda thoracica Olivier, 1795).

\section{Chave para as espécies de Sybaguasu}

1.1. Antenômeros III a VI pretos com curto anel branco apenas no extremo basal; élitros com tegumento avermelhado e ápices brancos. Peru S. titingum

1'. Antenômero III parcialmente branco, ou III e IV brancos, ou V e VI brancos; élitros com tegumento preto sem ápices brancos

2. Antenômero VI inteiramente branco; [cabeça (fêmea) revestida por densa pubescência branca; pronoto com densa pubescência branca menos na base que é transversalmente preta]. Fig. 8. Panamá (Chiriqui) ........ S. anemum sp. nov.

2'. Antenômero VI preto ou com a base branca .................... 3

3. Somente o antenômero IV com tegumento branco. Equador S. longipenne

3'. Antenômero IV e, pelo menos, parte do V com tegumento branco 4

4. Epipleura com pubescência branca; fronte dos machos sem projeções

4'. Epipleura preta, sem pubescência branca; fronte dos machos dois com pequenos tubérculos. Guiana Francesa, Brasil (Pará) S. thoracicum

5. Carena elitral terminada antes do meio. Panamá S. subcarinatum

5 '. Carena elitral prolongada até quase o ápice com anel basa amare; escapo bem curvo na base. Peru, Brasil (Amazonas, Pará) S. pubicorne

$6^{\prime}$. Friso sutural preto; antenômero III com anel basal e terço apical amarelos; escapo quase reto. Colômbia, Equador .. S. murinum

\section{Sybaguasu anemum sp. nov.}

Fig. 8

Etimologia. Tupi, anêma = amigo.

Macho. Cabeça e protórax avermelhados. Antenas pretas com o extremo apical do antenômero IV, antenômeros V e VI, brancos. Cabeça avermelhada com faixa de pubescência branca compacta atrás dos élitros. Escapo sem curvatura basal. Antenômeros III e IV com curta região basal amarelada; estes com pêlos internos, densos, que se prolongam até o antenômero VI. Protórax com faixa larga, lateral, de pubescência branca; base do pronoto com faixa transversal preta. Élitros (Fig. 8) pretos com epipleuras e friso sutural concolores; carena elitral prolongada até quase o ápice. Extremidades com espinho evidente no lado externo. Face ventral, pro- e mesofêmures avermelhados; metafêmures com a metade apical preta; tíbias e tarsos pretos.

Fêmea. Cabeça revestida por pubescência branco-amarelada, exceto em duas linhas longitudinais dos lobos oculares superiores ao occipício. Antenômeros III e IV pretos; franja de pêlos no lado interno densa e mais curta que a dos machos. Antenômeros V e VI brancos. Protórax densamente recoberto por pubescência branca menos numa área centro-posterior, avermelhada e preta. Úmeros com pequena mancha amarelada. Próe mesofêmures com a base avermelhada e gradualmente mais escuros dos anteriores para os posteriores. Urosternitos III e IV com densa pubescência branco-amarelada.

Dimensões em milímetros, respectivamente macho/fêmea. Comprimento total, 9,6-9,7/11,0;comprimento do protórax, 1,7-1,9/2,0; maior largura do protórax, 2,0-2,1/2,8; comprimento do élitro, 7,1-7,5/8,3 largura umeral, 2,5-2,7/3,5.

Material-tipo. Holótipo macho proveniente do PanamÁ, Chiriqui: Continental Divide Trail (on the Gualaca/Chiriqui Grande Highway), 12-14.V.1999, Wappes \& Morris leg. (USNM). Parátipos - mesma localidade (3600'), fêmea, 16-17.V.1996, Wappes, Huether \& Morris leg. (MZSP); Panamá, Chiriqui: Reserva La Fortuna (Finca La Suiza), macho, 25.V.1993, E. G. Riley leg. (ACMB).

Discussão. Apenas Sybaguasu subcarinatus ocorre no Panamá. Sybaguasu anemum sp. nov. distingue-se de $S$. carinatus pela carena dos élitros que quase atinge a ponta. Em $S$. subcarinatus a carena dos élitros não atinge o meio.

\section{Cuicirama spectabilis (Blanchard, 1843)}

Hemilophus spectabilis Blanchard, 1843: 210, est. 22, fig. 10. Cuicirama spectabilis; Martins \& Galileo, 1992: 124.

Originalmente descrita de Guarayos, Bolívia, coletada durante a viagem de D'Orbigny. Segundo Papavero (1971), Alcide d'Orbigny saiu de San Javier em 19 de dezembro de 1831 para explorar a vila dos índios Guarayos, onde permaneceu até 25.I. 1832. Essa localidade situa-se no Departamento de Beni e o holótipo foi coletado entre a segunda quinzena de dezembro de 1831 e 25.I.1832.

Material examinado. Bolívia, Santa Cruz: Buena Vista (3,7 km SSE, Hotel Flora e Fauna, 430 m), macho, 5-15.XI.2001, M.C. Thomas \& B.K. Dozier leg. "blacklight trap, tropical transition forest" (ACMB); Provincia Ichilo (El Cairo), macho, 13.XII.1995, Rap leg. (MCNZ).

\section{Apypema yara Galileo \& Martins, 1992}

Apypema yara Galileo \& Martins, 1992: 17, fig. 2; Monné, 1995: 18 (cat.).

Descrita originalmente do Peru (Huanuco) com base numa fêmea. O segundo exemplar examinado amplia a distribuição para o Brasil. 
Material examinado. Brasil, Rondônia: Cacaulândia (62 km SSE de Ariquemes, próximo à Fazenda Rancho Grande), fêmea, 4-16.XI.1997, J.E. Eger leg., Coleção R.F. Morris (ACMB).

\section{AGRADECIMENTOS}

A Jim E. Wappes (ACMB), Frank T. Hovore (FTHC) e R. H. Turnbow (RHTC) pela remessa de material para estudo; a Antonio Santos Silva (MZSP) pela execução das fotografias.

\section{REFERÊNCIAS BIBLIOGRÁFICAS}

AuriviLlius, C. 1923. Coleopterorum Catalogus, pars 74, Cerambycidae: Lamiinae. Berlin, W. Junk, p. 323-704.

Bates, H.W. 1881. Notes on longicorn Coleoptera. Revision of the aerénicides and amphionychides of tropical America. Annals and Magazin of Natural History, London, (5) 8: 290-306.

BLANCHARD, C.E. 1843. Insectes de l'Amérique méridionale, recueillis par Alcide D'Orbigny (Tribu des Longicornes). In: Voyage dans l'Amérique méridionale (le Brésil, la République Orientale de l'Uruguay, la République Argentine, la Patagonie, la République du Chili, la République de Bolivia, la République du Pérou), exécute pendant les années 1826, 1827, 1828, 1829, 1830, 1831, 1832 et 1833 par Alcide D'Orbigny. Paris, v. 6 (2), 222p.

Chabrillac, F. 1857. Description de treize espèces de cérambycides. Archives Entomologiques, Paris, 1: 194-200.

GaHAN, C.J. 1889. On new lamiide Coleoptera in the British Museum collection. Annals and Magazin of Natural History, London, (6) 3: 387-400.

Galileo, M.H.M. \& U.R. Martins. 1992. Os gêneros de Hemilophini (Coleoptera, Cerambycidae) com flagelômeros basais densamente pilosos e sem carena umeral. Revista brasileira de Entomologia, S. Paulo, 36 (1): 15-19.

. 1997. Transferência de espécies de Adesmus para Zeale, Ibitiruna gen. n. e Cuiciuna gen. n. (Coleoptera, Ceram- bycidae, Lamiinae, Hemilophini). Iheringia, Sér. Zoologia, Porto Alegre, (82): 159-172.

. 1999. O gênero Adesmus (Coleoptera, Cerambycidae, Lamiinae, Hemilophini). Iheringia, Sér. Zoologia, Porto Alegre (86): 77-116.

GounelLe, E. 1909. Liste de cérambycides de la région de Jatahy, État de Goyaz, Brésil. Annales de la Societé Entomologique de France, Paris, 77: 587-688.

Lane, F. 1956. Cerambycoidea Neotropica nova IV (Coleoptera). Dusenia, Curitiba, 7 (1): 1-32.

Martins, U.R. \& M.H.M. Galileo. 1991. Gêneros de Hemilophini (Coleoptera, Cerambycidae, Lamiinae) relacionados com Malacoscylus Thomson, 1868. Revista Brasileira de Entomologia, São Paulo, 35 (3): 619-629.

. 1992. Gêneros de Hemilophini (Coleoptera, Cerambycidae, Lamiinae) relacionados com Hemilophus A.-Serville, 1835. Revista Brasileira de Entomologia, São Paulo, 36 (1): 121-128.

1993. Cerambycidae (Coleoptera) of the Canadian Museum of Nature, Ottawa. IV. Hemilophini (Lamiinae). Insecta Mundi, Gainesville, 7 (3): 169-173.

. 1998. Gêneros de Hemilophini (Coleoptera, Cerambycidae) semelhantes a Phoebe Audinet-Serville, 1835. Revista Brasileira de Entomologia, São Paulo, 41 (2/4): 431-437.

Monné, M.A. 1995. Catalogue of the Cerambycidae (Coleoptera) of the western hemisphere. Part XX. São Paulo, Sociedade Brasileira de Entomologia, 119p.

Papavero, N. 1971. Essays on the History of Neotropical Dipterology. São Paulo, Museu de Zoologia, Universidade de São Paulo, vol. 1, VIII+216p.

Tippmann, F.F. 1960. Studien über neotropische Longicornier III (Coleoptera, Cerambycidae). Koleopterologische Rundschau, Wien, 37-38: 82-217.

ZAJCIW, D. 1967. Contribuições para o estudo da distribuição geográfica dos longicórneos no Brasil. Atas da Sociedade Biológica, Rio de Janeiro, 11 (1): 13-14.

Recebido em 02.III.2003; aceito em 19.VII.2004. 